\title{
Prevalence of baseline polymorphisms for potential resistance to NS5A inhibitors in drug-naive individuals infected with hepatitis $C$ genotypes 1-4
}

Adele L McCormick, Lawrence Wang, Ana Garcia-Diaz, Malcolm J Macartney, Daniel P Webster, Tanzina Haque

Antiviral Therapy 2014; 10.3851/IMP2763

Submission date 26th November 2013

Acceptance date 19th February 2014

Publication date 12th March 2014

For information about publishing your article in Antiviral Therapy go to http://www.intmedpress.com/index.cfm?pid=12 


\section{Short communication}

\section{Prevalence of baseline polymorphisms for potential resistance to NS5A inhibitors in drug- naive individuals infected with hepatitis $C$ genotypes 1-4}

Adele L McCormick ${ }^{1 *}$, Lawrence Wang ${ }^{1,2}$, Ana Garcia-Diaz ${ }^{1}$, Malcolm J Macartney ${ }^{1}$, Daniel $P$ Webster ${ }^{1}$, Tanzina Haque ${ }^{1}$

${ }^{1}$ Department of Virology, Royal Free London NHS Foundation Trust, London, UK

${ }^{2}$ Present address: Department of Biology, Haverford College, Haverford, PA, USA

*Corresponding author e-mail: adele.mccormick@nhs.net

\section{Abstract}

Background: The non-structural 5A (NS5A) protein of HCV is a multifunctional phosphoprotein involved in regulation of viral replication and virion assembly. NS5A inhibitors targeting domain I of NS5A protein have demonstrated high potency and pan-genotypic antiviral activity, however they possess a low genetic barrier to resistance. At present, only genotype 1, the most prevalent HCV genotype has been studied in detail for resistant variants.

Methods: Utilising a panel of genotypic-specific resistance assays, population sequencing was performed on plasma derived viral RNA isolated from 138 patients infected with HCV genotypes 1-4 and not treated with directly acting anti-viral agents (DAAs). Amino acid changes in HCV NS5A domain I at codon positions $28,30,31,32$ and 93 , reported to confer reduced susceptibility to certain NS5A inhibitors were examined. Additionally, genotypic outcome based on NS5A sequences were compared with LiPA and Abbott ${ }^{\mathrm{B}}$ real time.

Results: Amino acid substitutions associated with moderate to high level resistance to NS5A inhibitors were detected in 2/42 (4.76\%) HCV-1a, 3/23 (13.04\%) HCV-1b, 4/26 (15.38\%) HCV-2, 1/24 (4.17\%) HCV-3 and 1/23 (4.35\%) HCV-4 infected patients who had not been treated with NS5A inhibitors. Genotype prediction based on NS5A sequences were concordant with LiPA and/or Abbott ${ }^{\circledR}$ real-time for $97.10 \%$ of cases.

Conclusions: Primary resistance mutations associated with resistance to first generation NS5A inhibitors such as Daclatasvir (DCV) were observed in all genotypes, albeit at low frequencies. An excellent correlation based on NS5A genotyping and LiPA or Abbott ${ }^{\circledR}$ real-time was achieved.

Accepted 19 February 2014, published online 12 March 2014

Running head: NS5A inhibitor resistance-associated polymorphisms 


\section{Introduction}

A number of direct-acting antiviral agents (DAAs) targeting protease or polymerase enzymes encoded by hepatitis $C$ virus $(\mathrm{HCV})$ are under development or in clinical trials for the treatment of HCV. NS5A, a membrane-associated phosphoprotein of $\mathrm{HCV}$, plays a crucial role in regulating viral replication and host cell interactions [1,2]. NS5A inhibitors targeting domain I of NS5A protein are promising with their pan-genotypic antiviral activity and once daily dosing. Their resistance profiles do not overlap with other DAAs, and therefore can provide IFN-free treatment options in combination with other DAAs.

NS5A inhibitor monotherapy rapidly leads to emergence of resistant associated variants $[3,4]$. The efficacy of DAAs can be genotype/subtype dependent, mainly due to HCV diverse genetic variability, mainly due to the presence of natural polymorphisms associated with resistance. Polymorphisms in the N-terminus domain I of NS5A, with amino acid changes at positions M28T, $\mathrm{Q} 30 \mathrm{E} / \mathrm{H} / \mathrm{R}$, L31M/V, P32L, Y93C/H/N and L31F/V and $\mathrm{Y} 93 \mathrm{H} / \mathrm{N}$ for genotypes $1 \mathrm{a}$ and $1 \mathrm{~b}$ respectively confer resistance to NS5A inhibitors based on in vitro and in vivo data [4-7].

As the majority of NS5A resistance data is based primarily from patients infected with genotype 1 , the aim of this study was to assess the prevalence of NS5A domain I resistance associated polymorphisms in NS5A DAA naïve HCV patients infected with genotypes 1-4. Secondly, we evaluate a panel of NS5A resistance assays as potential genotypic predictor tools.

\section{Methods}

HCV RNA was quantified using Abbott $^{\circledR}$ real-time assay and genotyped using Abbott ${ }^{\circledR}$ real-time genotyping assay based on 5' UTR sequences, with genotype 1 further subtyped into $1 \mathrm{a}$ or $1 \mathrm{~b}$ by NS5B sequencing. Prior to 2010, genotyping was performed using VERSANT® HCV genotype 2.0 assay (LIPA) (Siemens Healthcare, Surrey, UK), targeting core and 5' UTR.

The entire 213 amino acids of NS5A domain I were amplified from plasma derived HCV viral RNA, using Qiagen ${ }^{\circledR}$ one-step RT-PCR system (Qiagen, Crawley, UK), and nested PCR using HotStarTaq PCR (Qiagen, Crawley, UK), incorporating HCV genotype/subtype specific primers (Table 1). Purified PCR amplicons were sequenced using ABI PRISM 3730 Genetic Analyser (Applied Biosystem, Paisley, UK). Consensus sequences were aligned against HCV reference sequences using SeqScape v3.0 (Applied Biosystem, Paisley, UK), and translated into amino acid using Bioedit version 7.2.3 to determine the prevalence of resistant-associated natural polymorphisms. HCV genotypes based on NS5A sequences were compared with those obtained either by LiPA or Abbott ${ }^{\circledR}$ assay. Core/E1 and NS5B sequencing was performed on discrepant specimens for confirmation purposes and to identify potential recombination events [8]. 


\section{Results}

PCR amplicons covering the entire HCV NS5A domain I of genotypes 1-4 were successfully generated for $138 \mathrm{HCV}$ patients. Table 2 depicts the prevalence of amino acid polymorphisms associated with resistance to NS5A inhibitors. Amino acid substitutions associated with NS5A inhibitor resistance at codons $28,30,31$ and 93 , existed but were relatively rare events across genotype.

Of forty-two HCV-1a infected patients, only two (4.76\%) harboured mutations associated with loss of activity for Daclatasvir (DCV), a first generation NS5A inhibitor. One patient harboured a $\mathrm{Q} 30 \mathrm{H} / \mathrm{Q}$ and $\mathrm{Y} 93 \mathrm{H} / \mathrm{Y}$ mixture, the presence of $\mathrm{Q} 30 \mathrm{H}$ and $\mathrm{Y} 93 \mathrm{H}$ on the same viral genome confers 93,136 fold resistance to DCV [9]. A second patient contained M28V and Q30R, reported to confer 350 fold resistance to DCV [9], whilst in two patients, the M28M/V mixture existed alone, conferring minimal DCV resistance (1.3 fold change) [6]. Additionally, only three HCV-1a patients had the baseline variant E62D, which on its own does not confer DCV resistance [10].

Three $(13 \%)$ of the $23 \mathrm{HCV} 1 \mathrm{~b}$ patients contained amino acid substitutions involved in NS5A resistance. One patient contained $\mathrm{Y} 93 \mathrm{H}$, conferring 19-24 fold resistance compared with wild type $[6,9]$ whilst a second patient harboured $\mathrm{Y} 93 \mathrm{H} / \mathrm{Y}$ mixture. L31M was observed in the third patient, which confers 3-fold DCV resistance [6].

Of 26 HCV-2 infected patients, four (15.38\%) contained L31M. The NS5A M31 is a common genotype 2 variant $[>50 \% ; 11]$ and was observed in all four HCV-2a patients genotyped, conferring 350 fold DCV resistance. Additionally, thirteen HCV-2b patients harboured S58P polymorphism, and one HCV-2c patient contained K30R polymorphism, both variants conferring minimal DCV resistance effects.

Only one of $24 \mathrm{HCV}-3$ patients harboured an amino acid substitution implicated in DCV resistance, at codon 30 (A30K). The A30K polymorphism has been reported to confer 44-62 fold resistance and a replicative capacity of $66 \%$ compared to wild type in a genotype 3 replicon model $[12,13]$. Both L31F and Y93H polymorphisms associated with DCV resistance in vitro for genotype 3 were not observed in this cohort [13].

Finally, of $23 \mathrm{HCV}-4$ patients, a single patient harboured a serine at codon 30 , instead of an arginine $(14 / 23)$ or leucine $(8 / 23)$ at this position, and associated with 167 fold resistance to DCV based on genotype 4 in vitro replicon model [15]. Additionally, the majority of NS5A sequences 21/23 (91.30\%) harboured L31M, also reported elsewhere in HCV-4, with unknown effects [14]. Interestingly, two patients who harboured a leucine instead of methionine at codon 31 (L31), genotyped as HCV-4r based on NS5A, NS5B and Core sequences. Overall, HCV genotyping based on NS5A sequences were concordant with LiPA or Abbott $^{\circledR}$ real-time for $134 / 138$ (97.10\%) of HCV patients. Among the four discordants, two specimens genotyped as HCV-1b by LiPA were subsequently genotyped as HCV-1a on NS5A, Core/E1 and NS5B sequencing. One specimen that could not be genotyped by LiPA (designated as either HCV-1 or HCV-4) and another specimen 
originally genotyped as HCV-4 by Abbot real-time, genotyped as HCV-4r when NS5A, Core/E1 and NS5B nucleotide sequences were submitted to http://blast.ncbi.nlm.nih.gov/Blast.cgi.

\section{Discussion}

NS5A inhibitors have shown to have pan-genotypic activity; however, there is limited data on the prevalence of natural polymorphisms associated with resistance to NS5A inhibitors, other than genotype 1. NS5A resistance variants frequently pre-exist among HCV patients and thus there is currently a need for genotypic predictions prior to combination therapy to establish optimal use of NS5A inhibitors.

Overlapping resistance signatures are common among NS5A inhibitors in development $[3,14]$. This study provides the first data on the prevalence of polymorphisms in HCV NS5A domain I for genotypes 1 to 4 . In this cohort of 138 patients we were able to detect natural polymorphisms in HCV NS5A domain I, reported to confer moderate to high level resistance to NS5A inhibitors in all genotypes investigated. The prevalence of these signature polymorphisms differed according to genotype/subtype in that NS5A resistance associated polymorphisms were detected in $4.76 \% \mathrm{HCV}$ 1a; $13.04 \%$ HCV-1b; $15.38 \%$ HCV-2; 4.17\% HCV-3 and 4.35\% in HCV-4. These findings are in contrast to the data by Plaza et al, 2012 [14], where resistance-associated polymorphisms were only detected in HCV-1b and HCV-4 and absent in HCV-1a and HCV-3, with no available data for HCV-2.

The level of resistance conferred by these natural polymorphisms varies considerably depending upon the amino acid residue and the genetic backbone [6]. In our HCV-1a cohort, the most common resistant-associated variant was at codon $30(\mathrm{Q} 30 \mathrm{H}$ or $\mathrm{Q} 30 \mathrm{R})$, followed by $\mathrm{Y} 93 \mathrm{H}$, similar to the frequency reported in the European HCV database. The major resistant variant observed in two HCV-1b patients was at codon $93(\mathrm{Y} 93 \mathrm{H})$, which predominated over L31M, detected in only a single patient, and supports findings by others [16]. In HCV-2, NS5A L31M polymorphism was observed at a prevalence of $15.38 \%$, which confers 75 fold resistance to NS5A inhibitor, IDX719 [11] and 350 fold DCV resistance. Polymorphisms conferring minimal DCV resistance effects were also observed in HCV-2. For HCV-3, which was least polymorphic, only NS5A A30K resistant variant was observed in a single patient. For HCV-4 NS5A sequences, only one patient harboured the S30 resistant variant, and has been implicated as an important site for DCV resistance in vitro [15].

Although available clinical data indicates that baseline polymorphisms or heterogeneity of NS5A sequencing in HCV infected patients has minimal impact on NS5A inhibitor potency, it may significantly affect signature of resistance that emerges [11]. From our observations and others, baseline resistance testing for HCV-2 may be warranted.

Due to a large proportion of HCV quasispecies pre-existing in infected individuals, variants that confer resistance to anti-viral agents can be rapidly enriched and selected during anti-viral therapy [3]. There is a direct correlation between resistant variants emerging in vivo with DCV therapy and variants observed in vitro, with certain variants persisting months after treatment therapy [17]. 
Analysis of emergent resistant variants during virological failure is warranted to determine an association with baseline NS5A polymorphisms and to guide future treatment options.

In this study, we obtained excellent concordance between LiPA, Abbott@ real time assay and NS5A sequencing as a genotype predictor tool for $97.10 \%$ of HCV sequences. In addition, based on NS5A sequencing we were able to genotype four discordant specimens that were either misclassified or unable to be genotyped by commercial assays. Our observation of two cases of HCV-1a misclassified as HCV-1b by LiPA has been published elsewhere [8], and attributed to the low heterogeneity of 5'UTR.

A limitation of our study is the small data set of non-genotype $1 \mathrm{HCV}$ infected patients and the use of population sequencing which detects variants at $20 \%$ compared with ultra-deep sequencing detecting minority variants below $1 \%$. Future work on a larger cohort including NS5A DAA treated patients and studying the entire NS5A gene (domains I, II and III) will be informative.

\section{Disclosure Statement:}

I can confirm as the corresponding author and on behalf of the co-authors that there are no conflicts of interest involved with this article. However, Dr D P Webster has attended Advisory Boards for MSD and Gilead and received speaker fees from BMS, Gilead, MSD and Janssen, and received educational grants from BMS, Janssen, ViiV, Roche and Gilead to attend conferences.

\section{References:}

1. Belda O, Targett-Adams P. Small molecule inhibitors of the hepatitis $C$ virus-encoded NS5A protein. Virus Res 2012; 170:1-14.

2. Gao M. Antiviral activity and resistance of HCV NS5A replication complex inhibitors. Curr Opin Virol 2013; 3:1-7.

3. Fridell RA, Wang $\mathrm{C}$, Sun $\mathrm{JH}$, et al. Genotypic and phenotypic analysis of variants resistant to hepatitis $\mathrm{C}$ virus non-structural protein 5A replication complex inhibitor BMS-790052 in humans: in vitro and in vivo correlations. Hepatology 2011; 54:1924-1935.

4. Lawitz EJ, Gruener D, Hill JM, et al. A phase 1, randomized placebo-controlled, 3-day, doseranging study of GS-5885, an NS5A inhibitor, in patients with genotype 1 hepatitis C. $J$ Hepatol 2012; 57:24-31.

5. Gao M, Nettles R, Belema M, et al. Chemical genetics strategy identifies an HCV NS5A inhibitor with a potent clinical effect. Nature 2010; 465:96-100.

6. Fridell RA, Qiu D, Wang C, Valera L, Gao M. Resistance analysis of the hepatitis C virus NS5A inhibitor BMS-790052 in an in vitro replicon system. Antimicrob Agents Chemother 2010; 54:3641-3650.

7. Lok AS, Gardiner DF, Lawitz E, et al. Preliminary study of two antiviral agents for hepatitis C genotype 1. N Engl J Med 2012; 366:216-224.

8. Avó AP, Água-Doce I, Andrade A, Pádua E. Hepatitis $C$ virus subtyping based on sequencing of the C/E1 and NS5B genomic regions in comparison to a commercially available line probe assay. $J$ Med Virol 2013; 85:815-822.

9. Pawlotsky JM. NS5A inhibitors in the treatment of hepatitis C. J Hepatol 2013; 59:375-382.

10. Sun JH, O'Boyle DR, II, Zhang Y, et al. Impact of a baseline polymorphism on the emergence of resistance to the hepatitis $C$ virus non-structural protein $5 \mathrm{~A}$ replication complex inhibitor, BMS79005. Hepatology 2012; 55:1692-1699. 
11. Mayers DL, Vince B, Hill JM, et al. IDX719, HCV NS5A inhibitor, demonstrates pan-genotypic activity after three days of monotherapy in genotype 1,2, 3 or $4 \mathrm{HCV}$-infected subject. Hepatology 2012; 56:1020A.

12. Hernandez D, Zhou N, Ueland J, et al. Natural prevalence of NS5A polymorphisms in subjects infected with hepatitis $C$ virus genotype 3 and their effects on the antiviral activity of NS5A inhibitors. J Clin Virol 2013; 57:13-18.

13. Wang C, Valera L. Jia Lingling, Kirk MJ, Gao M, Fridell RA. In vitro activity of daclatasvir on hepatitis C virus genotype 3 NS5A. Antimicrob Agents Chemother 2013; 57:611-613.

14. Plaza Z, Soriano V, Vispo E, et al. Prevalence of natural polymorphisms at the HCV NS5A gene associated with resistance to daclatasvir, an NS5A inhibitor. Antivir Ther 2012; 17:921-926.

15. Wang $\mathrm{C}$, Lingling $\mathrm{L}$, Huang $\mathrm{H}$, et al. In vitro activity of BMS-790052 on hepatitis $\mathrm{C}$ virus genotype 4 NS5A. Antimicrob Agents Chemother 2012; 56:1588-1590.

16. Suzuki F, Sezaki H, Akuta N, et al. Prevalence of hepatitis $C$ virus variants resistant to NS3 protease inhibitors or the NS5A inhibitor (BMS-790052) in hepatitis patients with genotype $1 \mathrm{~b}$. J Clin Virol 2012; 54:352-354.

17. Karino $\mathrm{Y}$, Toyota J, Ikeda $\mathrm{K}$, et al. Characterization of virologic escape in hepatitis $\mathrm{C}$ virus genotype $1 \mathrm{~b}$ patients treated with the direct-acting antivirals daclatasvir and asunaprevir. $J$ Hepatol 2013; 58:646-654. 
Publication: Antiviral Therapy; Type: Short communication

DOI: $10.3851 / \mathrm{IMP} 2763$

Table 1: Genotypic specific oligonucleotides used for PCR amplification of HCV NS5A domain 1

\begin{tabular}{|c|c|c|c|c|}
\hline $\begin{array}{c}\text { HCV } \\
\text { genotype/ } \\
\text { subtype }\end{array}$ & Primer name & 5'-3' nucleotide sequence & $\begin{array}{c}\text { Position } \\
\text { based on } \\
\text { H77 locus }\end{array}$ & $\begin{array}{l}\text { Primer } \\
\mathbf{T}_{\mathrm{m}}\end{array}$ \\
\hline $1 a$ & $\begin{array}{l}\text { RT PCR: } \\
\text { Out forward 1a } \\
\text { Out reverse 1a } \\
\text { Nested PCR: } \\
\text { In forward 1a } \\
\text { In reverse 1a }\end{array}$ & 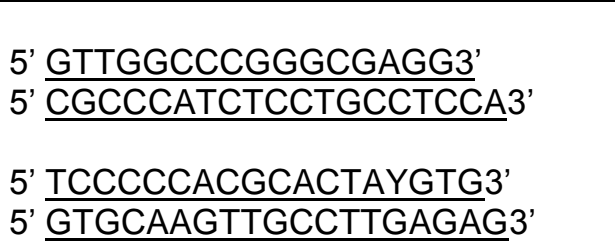 & $\begin{array}{l}6057-6072 \\
7038-7056 \\
6129-6146 \\
6970-6988\end{array}$ & $\begin{array}{l}58^{\circ} \mathrm{C} \\
58^{\circ} \mathrm{C}\end{array}$ \\
\hline $1 \mathrm{~b}$ & $\begin{array}{l}\text { RT PCR: } \\
\text { Out forward } 1 b \\
\text { Out reverse } 1 b \\
\text { Nested PCR: } \\
\text { In forward 1b } \\
\text { In reverse 1b }\end{array}$ & 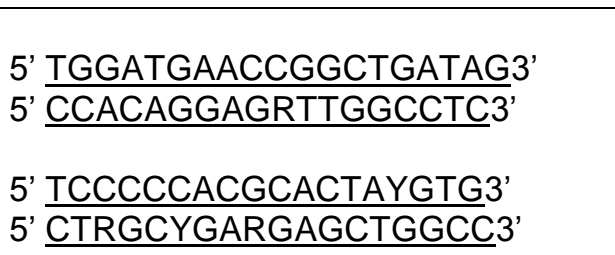 & $\begin{array}{l}6084-6102 \\
7023-7040 \\
6129-6146 \\
6935-6952\end{array}$ & $\begin{array}{l}57^{\circ} \mathrm{C} \\
57^{\circ} \mathrm{C}\end{array}$ \\
\hline 2 & $\begin{array}{l}\text { RT PCR: } \\
\text { Out forward } 2 \\
\text { Out reverse } 2 \\
\text { Nested PCR: } \\
\text { In forward } 2 \\
\text { In reverse } 2\end{array}$ & $\begin{array}{l}\text { 5' GCGGTCCAGTGGATGAACAG3' } \\
\text { 5' ACTCRATCCGGGTCACRTC3' } \\
\text { 5' CACTACGTGRCRGAGTCTG3' } \\
\text { 5' AGCTGGCTYGCTGARGAGC3' }\end{array}$ & $\begin{array}{l}6075-6094 \\
7059-7077 \\
6138-6156 \\
6940-6958\end{array}$ & $\begin{array}{l}57^{\circ} \mathrm{C} \\
57^{\circ} \mathrm{C}\end{array}$ \\
\hline 3 & $\begin{array}{l}\text { RT PCR: } \\
\text { Out forward } 3 \\
\text { Out reverse } 3 \\
\text { Nested PCR: } \\
\text { In forward } 3 \\
\text { In reverse } 3\end{array}$ & $\begin{array}{l}\text { 5' TGGATGAACAGGCTCATYGC3' } \\
\text { 5' ATGTTRCTGCCCATCTCTTG3' } \\
\text { 5' GTYCCCGAGAGCGATGCYGC3' } \\
\text { 5'AGTTGGCTGGRGAYGAGCTYGC3' }\end{array}$ & $\begin{array}{l}6084-6103 \\
7044-7063 \\
6144-6163 \\
6936-6958\end{array}$ & $\begin{array}{l}55^{\circ} \mathrm{C} \\
57^{\circ} \mathrm{C}\end{array}$ \\
\hline 4 & $\begin{array}{l}\text { RT PCR: } \\
\text { Out forward } 4 \\
\text { Out reverse } 4\end{array}$ & $\begin{array}{l}\text { 5' GATCATGAGYGGCGAG3' } \\
\text { 5' GAYGGRTCTGTCARCATGG3' }\end{array}$ & $\begin{array}{l}5942-5957 \\
6859-6877\end{array}$ & $55^{\circ} \mathrm{C}$ \\
\hline
\end{tabular}

Primers underlined have been modified with degeneracies and published elsewhere [14]. RT-PCR and Nested PCR conditions were performed according to the manufacturer. Primer annealing temperatures performed in RTPCR and nested PCR are shown. 
Publication: Antiviral Therapy; Type: Short communication

DOI: $10.3851 / \mathrm{IMP} 2763$

Table 2: Prevalence of NS5A domain I amino acid polymorphisms associated with resistance to NS5A inhibitor in HCV infected patients.

\begin{tabular}{|c|c|c|c|c|}
\hline $\begin{array}{l}\text { Genotype/ } \\
\text { Subtype }\end{array}$ & $\begin{array}{c}\text { Number } \\
\text { Patients } \\
\text { genotyped }\end{array}$ & $\begin{array}{l}\text { NS5A inhibitor resistance } \\
\text { associated polymorphisms }\end{array}$ & $\begin{array}{l}\text { DCV fold } \\
\text { resistance }\end{array}$ & Reference \\
\hline $1 \mathrm{a}$ & 42 & $\begin{array}{c}\text { Q30H/Q+Y93H/Y (1) } \\
\text { M28V+Q30R (1) }\end{array}$ & $\begin{array}{l}93,136 \\
350\end{array}$ & $\begin{array}{l}{[9]} \\
{[9]}\end{array}$ \\
\hline $1 b$ & 23 & $\begin{array}{c}\text { Y93H (1) } \\
\text { Y93H/Y (1) } \\
\text { L31M (1) } \\
\text { M28+Q30*(2) }\end{array}$ & $\begin{array}{c}19-24 \\
3\end{array}$ & $\begin{array}{c}{[6,9]} \\
{[6]}\end{array}$ \\
\hline $2 a$ & 4 & L31M (4) & $\begin{array}{l}75^{*} \\
350\end{array}$ & $\begin{array}{c}{[11]} \\
\text { www.geno2pheno.org }\end{array}$ \\
\hline $2 b$ & 13 & S58P (13) & 5 & www.geno2pheno.org \\
\hline $2 c$ & 6 & K30R (1) & 3 & www.geno2pheno.org \\
\hline $2 \mathrm{i}$ & 3 & none & - & - \\
\hline 3 & 24 & K30 (1) & $44-62$ & {$[12,13]$} \\
\hline 4 & 23 & $\begin{array}{c}\mathrm{S} 30(1) \\
\mathrm{L} 31^{* *}(2)\end{array}$ & 167 & [15] \\
\hline
\end{tabular}

Amino acid residues at codon positions associated with Daclatasvir (DCV) resistance are shown in bold type. Number of patients are shown in brackets. ₹ Fold resistance to IDX719 NS5A drug inhibitor. *Patients genotyped as $1 \mathrm{~b}$ by VERSANT LiPA 2.0 subsequently genotyped as $1 \mathrm{a}$ based on NS5A, Core/E1 and NS5B sequence data. ${ }^{* *}$ Patients genotyped as $4 \mathrm{r}$ based on NS5A, Core/E1 and NS5B data. 